\title{
Prediction of vaginal birth after cesarean delivery in Southeast China: a retrospective cohort study
}

Hua-Le Zhang ${ }^{1}$, Liang-Hui Zheng ${ }^{1}$, Li-Chun Cheng ${ }^{1}$, Zhao-Dong Liu', Lu Yu ${ }^{1}{ }^{12}$, Qin Han ${ }^{1}$, Geng-Yun Miao ${ }^{2}$ and Jian-Ying $\operatorname{Yan}^{1 *}$ (D)

\begin{abstract}
Background: We aimed to develop and validate a nomogram for effective prediction of vaginal birth after cesarean (VBAC) and guide future clinical application.

Methods: We retrospectively analyzed data from hospitalized pregnant women who underwent trial of labor after cesarean (TOLAC), at the Fujian Provincial Maternity and Children's Hospital, between October 2015 and October 2017. Briefly, we included singleton pregnant women, at a gestational age above 37 weeks who underwent a primary cesarean section, in the study. We then extracted their sociodemographic data and clinical characteristics, and randomly divided the samples into training and validation sets. We employed the least absolute shrinkage and selection operator (LASSO) regression to select variables and construct VBAC success rate in the training set. Thereafter, we validated the nomogram using the concordance index (C-index), decision curve analysis (DCA), and calibration curves. Finally, we adopted the Grobman's model to perform comparisons with published VBAC prediction models.

Results: Among the 708 pregnant women included according to inclusion criteria, 586 (82.77\%) patients were successfully for VBAC. Multivariate logistic regression models revealed that maternal height $(\mathrm{OR}, 1.11 ; 95 \% \mathrm{Cl}, 1.04$ to 1.19), maternal $\mathrm{BMI}$ at delivery $(\mathrm{OR}, 0.89 ; 95 \% \mathrm{Cl}, 0.79$ to 1.00), fundal height $(\mathrm{OR}, 0.71 ; 95 \% \mathrm{Cl}, 0.58$ to 0.88$)$, cervix Bishop score $(\mathrm{OR}, 3.27 ; 95 \% \mathrm{Cl}, 2.49$ to 4.45$)$, maternal age at delivery $(\mathrm{OR}, 0.90 ; 95 \% \mathrm{Cl}, 0.82$ to 0.98$)$, gestational age $(\mathrm{OR}, 0.33 ; 95 \% \mathrm{Cl}, 0.17$ to 0.62$)$ and history of vaginal delivery $(\mathrm{OR}, 2.92 ; 95 \% \mathrm{Cl}, 1.42$ to 6.48$)$ were independently associated with successful VBAC. The constructed predictive model showed better discrimination than that from the Grobman's model in the validation series (c-index 0.906 VS 0.694, respectively). On the other hand, decision curve analysis revealed that the new model had better clinical net benefits than the Grobman's model.

Conclusions: VBAC will aid in reducing the rate of cesarean sections in China. In clinical practice, the TOLAC prediction model will help improve VBAC's success rate, owing to its contribution to reducing secondary cesarean section.
\end{abstract}

Keywords: Mode of delivery decisions, Cesarean section, Vaginal birth, VBAC

\footnotetext{
* Correspondence: yanjy2019@fjmu.edu.cn

'Department of Obstetrics and Gynecology, Fujian Maternity and Child

Health Hospital, Affiliated Hospital of Fujian Medical University, No.18,

Daoshan Rd., Gulou Dist, Fuzhou City, Fujian province, China

Full list of author information is available at the end of the article
}

C C The Author(s). 2020 Open Access This article is licensed under a Creative Commons Attribution 4.0 International License, which permits use, sharing, adaptation, distribution and reproduction in any medium or format, as long as you give appropriate credit to the original author(s) and the source, provide a link to the Creative Commons licence, and indicate if changes were made. The images or other third party material in this article are included in the article's Creative Commons licence, unless indicated otherwise in a credit line to the material. If material is not included in the article's Creative Commons licence and your intended use is not permitted by statutory regulation or exceeds the permitted use, you will need to obtain permission directly from the copyright holder. To view a copy of this licence, visit http://creativecommons.org/licenses/by/4.0/ The Creative Commons Public Domain Dedication waiver (http://creativecommons.org/publicdomain/zero/1.0/) applies to the data made available in this article, unless otherwise stated in a credit line to the data. 


\section{Background}

Reducing the rate of cesarean section is a global consensus. However, increase in cesarean delivery (CD) seems uncontrollable, with no signs of slowing down [1]. In China, statistical data indicate that CD rate has increased, by $20.8 \%$, between 2008 and 2014, with this rate reportedly higher in certain regions [2]. Repeat cesarean delivery is the most important component, although implementation of the twochild policy has presented new challenges to reducing repeat cesarean delivery [3-5]. Since the 1970s, numerous studies have proposed the use of trial of labor after cesarean (TOLAC) as a strategy for reducing cesarean section rates, owing to the high success of VBAC ratio, coupled with associated low rates of adverse outcomes and cost effectiveness $[6,7]$. Consequently, several professional organizations have tended to subject their patients to TOLAC. In fact, clinical practice guidelines support this evidence-based practice across such circumstances. In China's tense doctor-patient relationships, clinical practice guidelines can be used at different levels of hospitals to support evidencebased practice during such circumstances. Among the existing clinical guidelines, Southeast China pays more attention to the 2015RCOG guidelines, with the subsequent release of Chinese guidelines also using these it as an important reference standard $[8,9]$. However, TOLAC's failure has been implicated in numerous perinatal risks, compared to elective repeated cesarean delivery without labor [10]. To avoid doctor-patient disputes, resulting from TOLAC failure, Chinese medical staff need an effective intervention. This calls for evaluation of TOLAC's efficacy before and after delivery. To date, however, numerous studies have only reported computational and individualized risk assessment for successful TOLAC [11, 12]. Moreover, some prediction and validation models have been developed for pregnant Chinese women [13-15], although these models are based on local clinical guidelines and lack inclusion criteria for TOLAC. Generally, medical staff in southeastern China are more likely to practice TOLAC, based on admission criteria described clinical guidelines. Therefore, development of a prediction model based on this demand may help to improve TOLAC practice and reduce CD rates. The present retrospective study aimed to build a personalized prediction model for successful application of TOLAC in a population, based on admission criteria described in clinical guidelines. This model is expected to guide evaluation of VBAC feasibility before delivery.

\section{Methods}

\section{Study design and data acquisition}

This retrospective observational study was performed using data obtained from a case register, at the Fujian Provincial Maternity and Children's Hospital A tertiary hospital in southeastern China between October 2015 and October 2017. This is a specialized hospital that serves nine prefecture-level cities, with an annual delivery volume of nearly 20,000 patients. Patient data, for this study, was extracted from medical records using pre-defined data fields.

\section{Selection criteria}

Inclusion and exclusion criteria were assessed by investigators, according to China's clinical guidelines for VBAC [9]. Summarily, inclusion criteria were as follows: women with a singleton pregnancy of cephalic presentation at 37 weeks or beyond, who have had a single previous lower segment caesarean delivery. The indications for the previous cesarean section did not appear again in this pregnancy before labour, such as abnormal fetal position, placenta previa, Oligohydramnios, severe preeclampsia, placental abruption, and twin pregnancy. In addition, all patients had an estimated fetal weight $>4000 \mathrm{~g}$, and had an intact lower segment uterine scar following ultrasound analysis. On the other hand, women with two or more prior caesarean sections, a classical cesarean scar or previous uterine rupture, as well as those who have other absolute contraindications to vaginal birth, were excluded from the study. Moreover, all participants had no diabetes, chronic hypertension, cardiac disease, asthma, renal disease, or a connective tissue disorder. Finally, all participants experienced spontaneous uterine contractions and did not induce labor.

\section{Study outcomes}

Primary outcomes were based on TOLAC's success rate. On the other hand, secondary outcomes comprised analysis of maternal features, such as uterine rupture, mortality, and post-partum hemorrhage (estimated blood loss of more than 500 and $1000 \mathrm{ml}$ for vaginal and cesarean deliveries, respectively), whereas neonatal outcome features included mortality, and neonatal asphyxia (defined as 5-min Apgar score $\leq 7$ ).

\section{Predictors}

Independent variables were extracted from medical record databases, based on values recorded at the time of development of spontaneous symptoms. Summarily, the extracted demographic information included age (on delivery date), maternal height, pre-gravid maternal weight, maternal weight at delivery, gravida, parity, abdominal, fundal height, cervix Bishop score (assessed after regular uterine contractions with abdominal pain for $2 \mathrm{~h}$ ), history of vaginal delivery and gestational age.

\section{Statistical analysis}

We used packages implemented in $\mathrm{R}$ software (V3.6.2) for all statistical analyses and generation of drawings, at a 95\% significance interval. Comparisons between demographic and clinical characteristics were performed by outcome status, using $\mathrm{t}$ tests or $\mathrm{X}^{2}$ tests. Construction and validation of the nomogram: To construct and validate 
the nomogram, we first incorporated clinical features as predictors, in its design. Summarily, $70 \%(n=483)$ of the participants were randomly assigned to the training cohort, whereas the rest of $(n=225)$ were assigned to the test cohort. We used the least absolute shrinkage and selection operator (LASSO) regression, with 5-fold cross-validation, to select the most useful predictive variables via 1se criteria for nomogram in the training cohort. In the test cohort, we first undertook internal validation, with a concordance index (C-index) estimation, then plotted calibration curves to determine concordance of the predicted and observed probabilities for survival time. Bootstrap resampling (1000 resamples) was used for this plot. Moreover, we evaluated clinical usefulness of the nomograms using decision curve analysis (DCA). Finally, we validated the Grobman's model [12], in the test cohort, and compared it with our model.

\section{Ethical approval}

This retrospective study was approved by the local institutional review boards and ethical committees. Written informed consent was not required because unidentifiable patient information used only.

\section{Results}

\section{Sample characteristics of the cohort}

A total of 5951 pregnant women with a history of previous CS were identified during the observation period. One thousand one hundred ninety-one of these participants had a vaginal delivery plan, after 36 weeks of pregnancy, and these comprised the sample for the candidate. Participants who changed their minds, for caesarean section during vaginal delivery by choice or family member influence, rather than based on medical indication, were excluded from the study. Eventually, 708 pregnant women, all Asian, were included in the final analysis (Fig. 1). The indications of previous caesarean section mainly include the following categories: breech or shoulder presentation (19.4\%), slow progress or arrest in labour (21.3), fetal distress (16.3\%), without medical indication (12.4\%), macrosomia (8.5\%), oligohydramnios $(6.9 \%)$, placenta previa $(2.7 \%)$, twin pregnancy $(2.4 \%)$, severe preeclampsia (1.6\%), placental abruption $(0.7 \%)$ and other indications. Clinical characteristics of the training $(n=483)$ and validation $(n=225)$ cohorts revealed no statistically significant differences between the groups (Table 1). Participants' mean maternal age, at delivery, was 31.28 (SD: 3.64) years whereas their median gestational period was 39 weeks (IQR: $38.29-39.86$ ). None of the pregnant women under this study experienced preeclampsia or gestational hypertension during pregnancy. The overall TOLAC success rate across the cohorts was $82.8 \%$. In addition, 5.5\% (39) of all women undergoing TOLAC were diagnosed with postpartum haemorrhage, $0.28 \%$ (2) had uterine rupture, with $0.14 \%$ (1) of new-borns experiencing neonatal asphyxia. In addition, no maternal death and hysterectomy were noted. TOLAC failure was attributed to abnormal stage of labour (34.4\%), fetal monitoring change (33.6\%), sharp lower abdominal pain (14.8\%), fever or abnormal bleeding $(9.8 \%)$ and other $(7.4 \%)$.

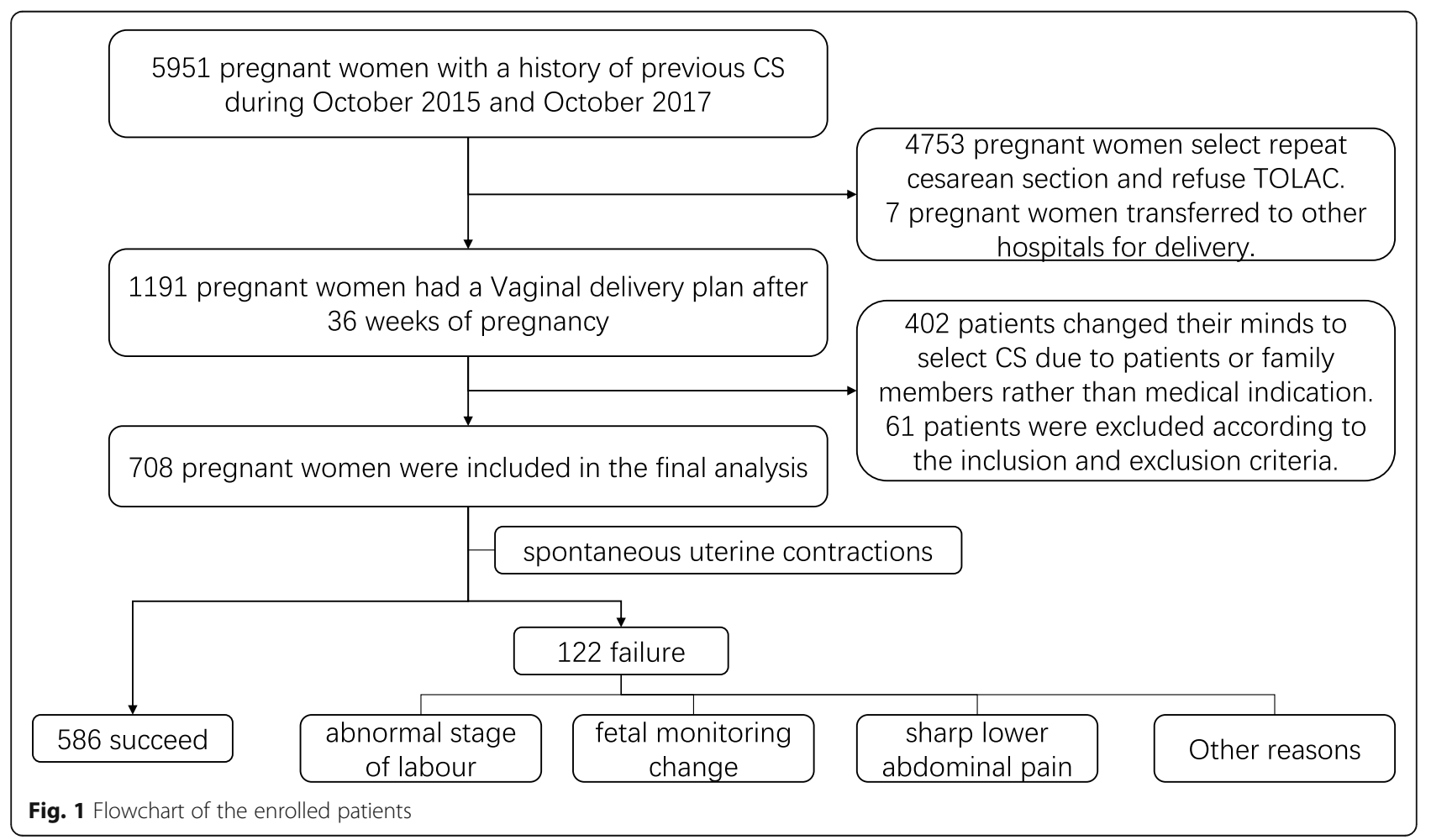


Table 1 Clinical characteristics of the training and validation cohorts

\begin{tabular}{|c|c|c|c|c|c|}
\hline \multicolumn{2}{|l|}{ Characteristics } & Whole cohort $(n=708)$ & Training cohorts $(n=483)$ & Validation cohorts $(n=225)$ & $P^{*}$ \\
\hline \multicolumn{2}{|l|}{ Maternal height (mean (SD)) } & $1.60(0.05)$ & $159.80(4.87)$ & $159.27(5.00)$ & 0.180 \\
\hline \multicolumn{2}{|c|}{ Pre-gravid maternal weight (mean (SD)) } & $53.27(7.19)$ & $53.43(7.43)$ & $52.93(6.64)$ & 0.383 \\
\hline \multicolumn{2}{|c|}{ Maternal weight at delivery (mean (SD)) } & $66.74(7.84)$ & $67.07(8.03)$ & $66.02(7.37)$ & 0.095 \\
\hline \multicolumn{2}{|c|}{ Pre-gravid maternal BMI (median [IQR]) } & $20.62[19.15,22.42]$ & $20.57[19.07,22.48]$ & $20.78[19.33,22.06]$ & 0.703 \\
\hline \multicolumn{2}{|c|}{ Maternal BMI at delivery (median [IQR]) } & $26.16[24.36,27.88]$ & $26.20[24.34,27.96]$ & $26.02[24.50,27.50]$ & 0.392 \\
\hline \multicolumn{2}{|c|}{ Abdominal circumference (mean (SD)) } & $98.37(5.05)$ & $98.44(5.23)$ & $98.21(4.62)$ & 0.582 \\
\hline \multicolumn{2}{|l|}{ Fundal height (mean (SD)) } & $33.87(1.50)$ & $33.91(1.57)$ & $33.78(1.31)$ & 0.253 \\
\hline \multicolumn{2}{|l|}{ Cervix Bishop score (median [IQR]) } & $7.00[7.00,8.00]$ & $7.00[7.00,8.00]$ & $7.00[7.00,8.00]$ & 0.909 \\
\hline \multicolumn{2}{|c|}{ Maternal age at delivery (mean (SD)) } & $31.28(3.64)$ & $31.23(3.58)$ & 31.39 (3.78) & 0.574 \\
\hline \multicolumn{2}{|l|}{ Gestation (median [IQR]) } & $39.00[38.29,39.86]$ & $1.00[0.00,1.00]$ & $1.00[0.00,1.00]$ & 0.334 \\
\hline \multicolumn{2}{|c|}{ Cesarean section interval time (median [IQR]) } & $5.00[3.00,7.00]$ & $5.00[3.00,6.50]$ & $4.00[3.00,7.00]$ & 0.942 \\
\hline \multirow[t]{2}{*}{ History of vaginal delivery (\%) } & NO & $473(66.8)$ & $319(66.0)$ & $154(68.4)$ & \multirow[t]{2}{*}{0.585} \\
\hline & YES & $235(33.2)$ & $164(34.0)$ & $71(31.6)$ & \\
\hline \multirow[t]{2}{*}{ Rupture of membranes (\%) } & NO & $473(66.8)$ & $332(68.7)$ & $141(62.7)$ & \multirow[t]{2}{*}{0.131} \\
\hline & YES & $235(33.2)$ & $151(31.3)$ & $84(37.3)$ & \\
\hline \multirow[t]{2}{*}{ Success of TOLAC (\%) } & NO & $122(17.2)$ & $86(17.8)$ & $36(16.0)$ & \multirow[t]{2}{*}{0.627} \\
\hline & YES & $586(82.8)$ & $397(82.2)$ & $189(84.0)$ & \\
\hline
\end{tabular}

*t test or $\mathrm{X}^{2}$ test; Mann-Whitney $\mathrm{U}$ test was applied for Non-normally distributed data

$I Q R$ interquartile range, $B M I$ Body Mass Index, $S D$ standard deviation

\section{Predictors of TOLAC success}

Univariate analysis revealed that maternal height, maternal BMI, parity, fundal height, cervix bishop score, duration of labour, maternal age, history of vaginal delivery and rupture of membranes were associated with successful TOLAC (Table 2). During nomogram development, we incorporated clinical characteristics as prognostic features, with all these parameters reduced to the most useful potential predictors during determination of the TOLAC's success rate in the training cohort, using the LASSO logistic regression model. Consequently, results from the LASSO logistic regression model were incorporated into the nomogram and used to predict success rate of TOLAC (Fig. 2). Summarily, maternal height,

Table 2 Sample characteristics based on TOLAC status

\begin{tabular}{|c|c|c|c|c|}
\hline Characteristics & & Failure of $\operatorname{TOLAC}(n=122)$ & Success of TOLAC $(n=586)$ & $P^{*}$ \\
\hline Maternal height (mean (SD)) & & $1.58(0.05)$ & $1.60(0.05)$ & $<0.001$ \\
\hline Pre-gravid maternal weight (mean (SD)) & & $53.55(7.56)$ & $53.21(7.11)$ & 0.635 \\
\hline Maternal weight at delivery (mean (SD)) & & $67.64(7.98)$ & $66.55(7.80)$ & 0.164 \\
\hline Pre-gravid maternal BMI (median [IQR]) & & $21.23[19.71,22.95]$ & $20.57[19.04,22.26]$ & 0.013 \\
\hline Maternal BMI at delivery (median [IQR]) & & $27.10[25.24,28.78]$ & $26.00[24.20,27.60]$ & $<0.001$ \\
\hline Parity (median [IQR]) & & $1.00[1.00,2.00]$ & $1.00[1.00,3.00]$ & $<0.001$ \\
\hline Abdominal circumference (mean (SD)) & & $98.56(5.26)$ & $98.33(5.00)$ & 0.639 \\
\hline Fundal height (mean (SD)) & & $34.32(1.60)$ & $33.78(1.46)$ & $<0.001$ \\
\hline Cervix Bishop score (median [IQR]) & & $6.00[4.00,6.00]$ & $8.00[7.00,8.00]$ & $<0.001$ \\
\hline Duration time of labor (median [IQR]) & & $7.00[4.00,10.75]$ & $5.57[4.10,8.30]$ & 0.044 \\
\hline Maternal age at delivery (mean (SD)) & & $31.87(3.57)$ & $31.16(3.64)$ & 0.049 \\
\hline Gestation (median [IQR]) & & $39.00[38.00,40.00]$ & $39.00[38.29,39.86]$ & 0.177 \\
\hline Cesarean section interval time (median [IQR]) & & $5.00[3.00,7.00]$ & $5.00[3.00,7.00]$ & 0.28 \\
\hline \multirow[t]{2}{*}{ History of vaginal delivery (\%) } & NO & $104(85.2)$ & $369(63.0)$ & $<0.001$ \\
\hline & YES & $18(14.8)$ & $217(37.0)$ & \\
\hline \multirow[t]{2}{*}{ PROM (\%) } & NO & $96(78.7)$ & $377(64.3)$ & 0.003 \\
\hline & YES & $26(21.3)$ & $209(35.7)$ & \\
\hline
\end{tabular}

*t test or $X^{2}$ test; Mann-Whitney $U$ test was applied for Non-normally distributed data 


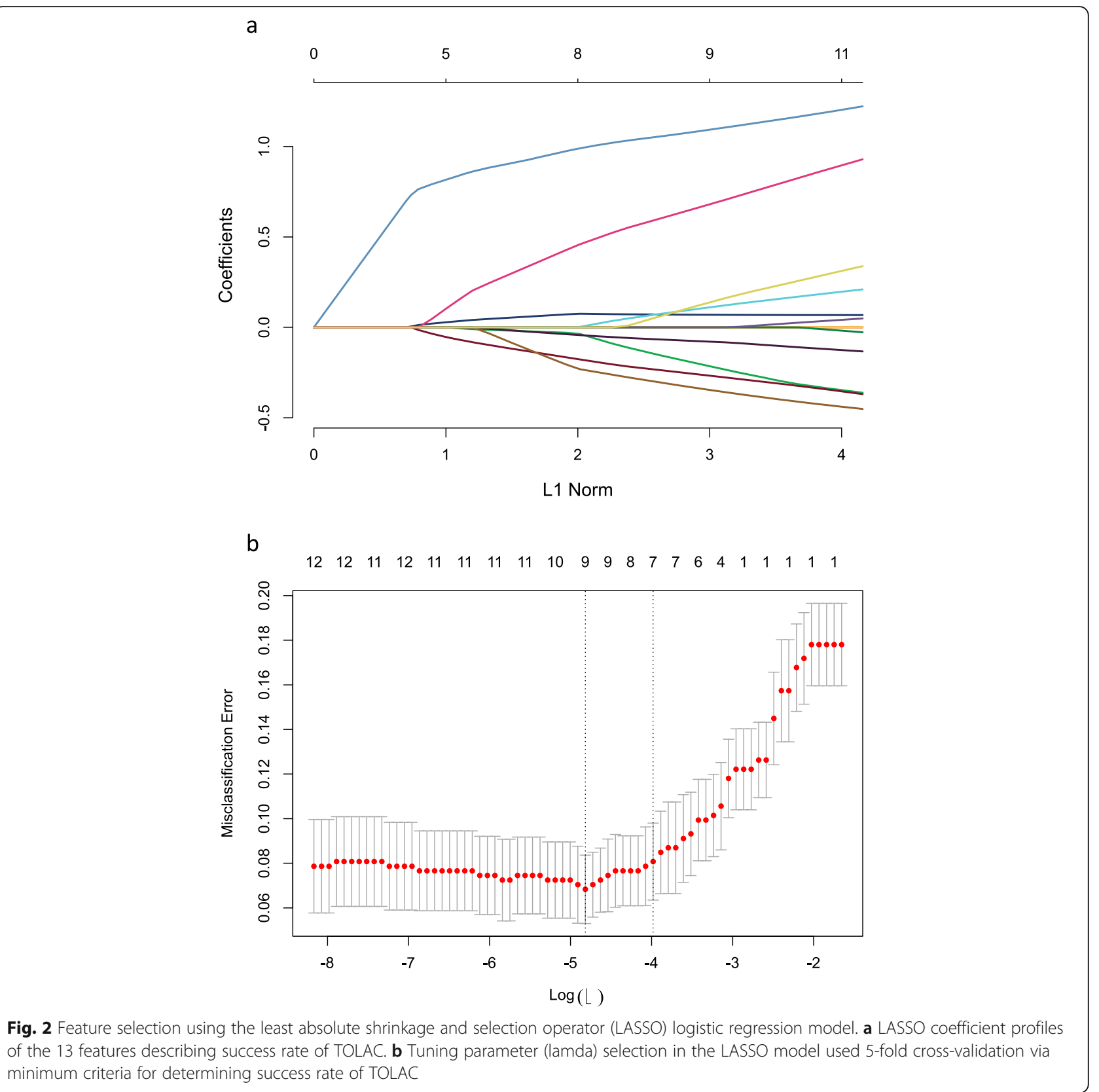

and BMI at delivery, fundal height, cervix Bishop score, maternal age at delivery, gestation period greater than 39 weeks and history of vaginal delivery were independent predictors for TOLAC (Fig. 3 and Table 3).

\section{Nomogram validation and compare}

Predictive accuracy, for the success rate of TOLAC as measured by $\mathrm{C}$-index was 0.89 in the internal validation. The calibration plot for the probability of TOLAC's success showed a strong correlation between the actual (observed) outcome and that predicted by the nomogram (Fig. 4a). In addition, we plotted calibration curves to evaluate performance of the newly-developed nomogram and Grobman's model in the test cohort, respectively (Fig. 4b and c). Results indicated that the newlydeveloped nomogram model was superior, to the Grobman's model, in predicting patients for inclusion in the standard according to clinical guidelines, based on data in Fig. 3. This was evidenced by both correlation and cindex (c-index: 0.90 vs 0.69 , respectively).

\section{Decision curve analysis}

Decision curves for newly-developed nomogram and Grobman's models, used to predict the rate of TOLAC in patients are illustrated in Fig. 4d. Here, the new model was useful, with threshold probabilities of $60-90 \%$. In 


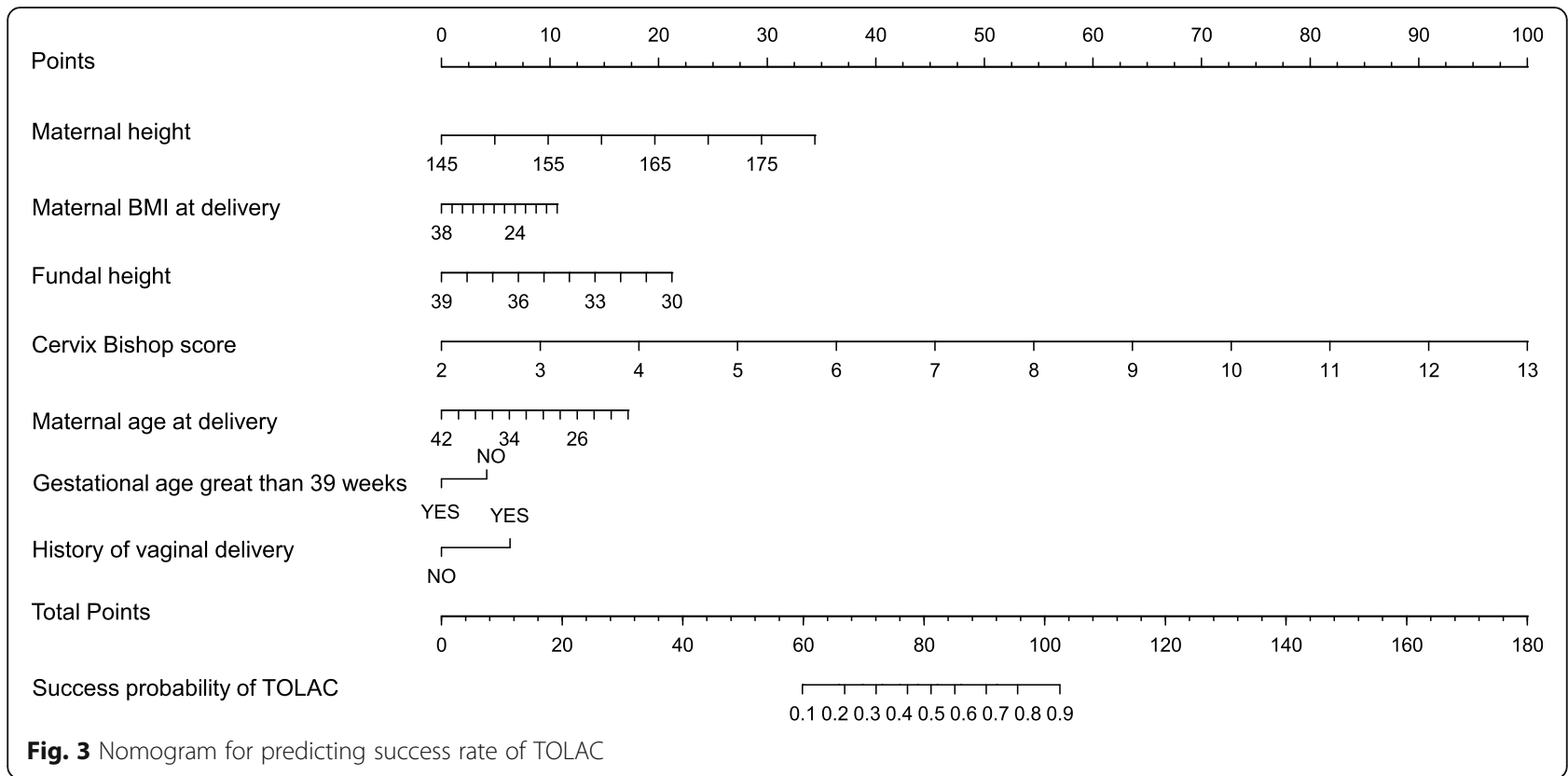

addition, the calibration curves revealed a higher success rate in actual vaginal delivery in this interval.

\section{Discussion}

Previous studies have described the importance of adopting TOLAC for reduction of $C D$ rates and improvement of maternal and child outcomes [6]. In fact, the Generalizing Grobman's model has been found to successfully predict the rate of TOLAC in Chinese populations, with a strong clinical predictive power [13, 15]. However, sample populations included in these studies have lacked uniform standards. Given the numerous efforts in clinical guidelines for obstetrics in China, in recent years, aimed at reducing medical disputes and improving the quality of healthcare, it is important to ensure accurate selection of patients to be predicted based on clinical guidelines. This is because prediction models are only applied to single patient populations selected based on similar inclusion and exclusion criteria as well as clinical management [16]. Since the rate of
TOLAC in China is very low, establishment of a reliable predictive model in low-risk pregnant women, without serious complications, is imperative to improving the TOLAC rate without too much medical risk. The present study aimed to identify factors that influence the success rate of TOLAC, and develop a predictive model to guide effective implementation of clinical guidelines. Particularly, we used external verification of the widely used Grobman's model, to add corresponding features before delivery, and achieved superior predictive ability.

Based on a clear trend of benefits from the successful vaginal delivery among those trials of labor after cesarean section, it is evident that VBAC failure exacerbates many risks, including bleeding, increased blood transfusions, uterine rupture and endometritis, as well as infant asphyxia or perinatal death $[8,17,18]$. Consequently, obstetricians prefer a more conservative approach during TOLAC to avoid medical disputes owing to the complex physician-patient relationship as well as the associated high work-related stress. When longer

Table 3 Predictors of TOLAC success rate based on the nomogram

\begin{tabular}{lllll}
\hline & $\boldsymbol{B}$ & SE & OR [95\%Cl] & \multicolumn{1}{c}{$\boldsymbol{P}$} \\
\hline (Intercept) & -5.29723 & 6.280949 & $0.01[0.00,1041.20]$ & 0.399 \\
Maternal height & 0.105889 & 0.035648 & $1.11[1.04,1.19]$ & 0.003 \\
Maternal BMI at delivery & -0.11339 & 0.058858 & $0.89[0.79,1.00]$ & 0.054 \\
Fundal height & -0.33551 & 0.108055 & $0.71[0.58,0.88]$ & $3.27[2.49,4.45]$ \\
Cervix Bishop score & 1.183312 & 0.147888 & $0.90[0.82,0.98]$ & 0.002 \\
Maternal age at delivery & -0.10831 & 0.044441 & $0.33[0.17,0.62]$ & 0.015 \\
Gestational age great than 39 weeks & -1.09738 & 0.323738 & $2.92[1.42,6.48]$ & 0.001 \\
History of vaginal delivery & 1.070891 & 0.385452 & & 0.005 \\
\hline
\end{tabular}

OR odds ratio, $\mathrm{Cl}$ confidence interval 


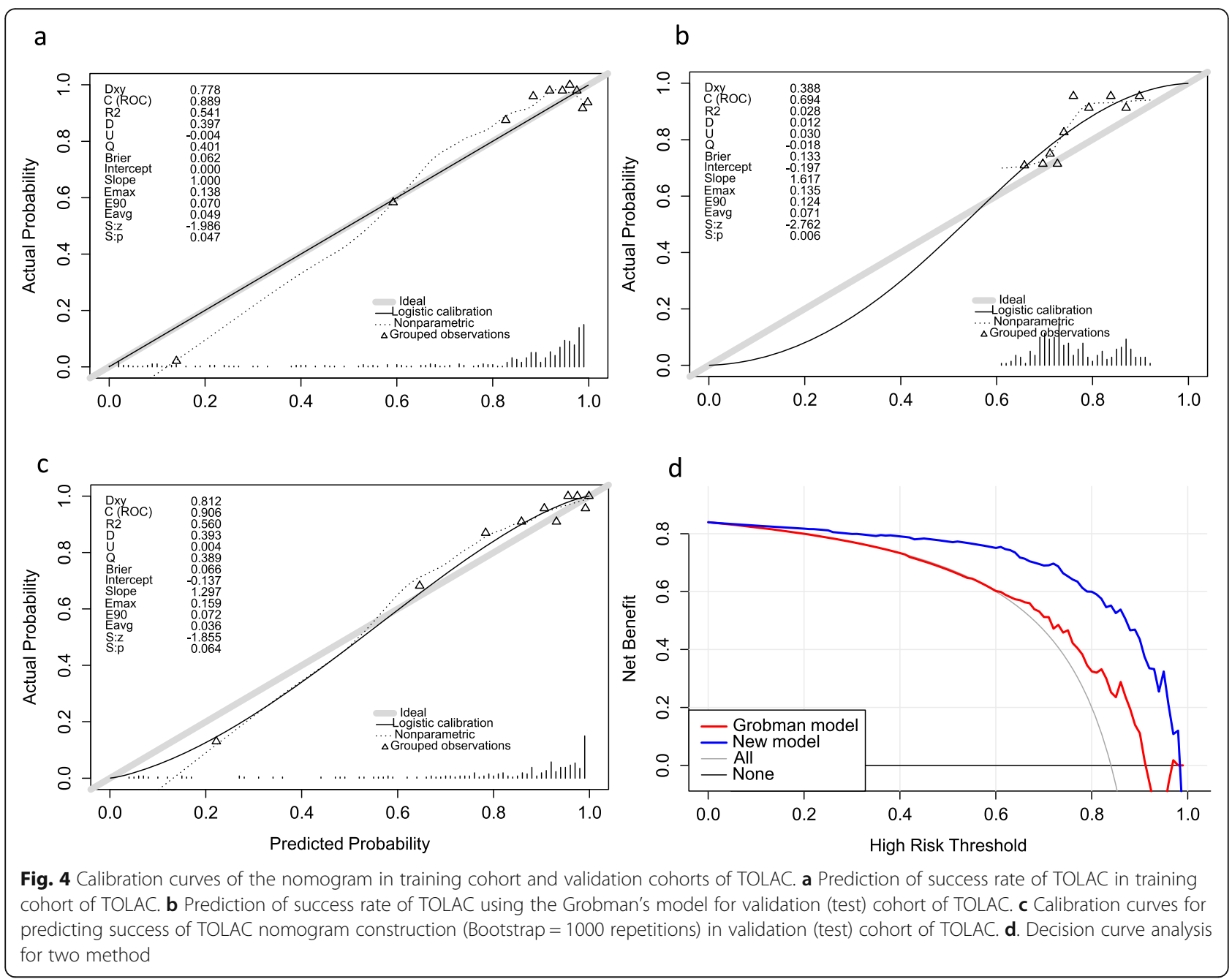

labor course or changes in fetal heart rate occur during TOLAC, doctors are more likely to perform repeat cesarean sections, in order to avoid the associated adverse consequences of uterine rupture or neonatal asphyxia. In the present study, our results indicate that the incidence of adverse clinical outcomes, such as uterine rupture and neonatal asphyxia, are lower than what has previously been reported. However, this strategy also significantly reduces TOLAC's success rate. In the present study, the described risk model had several advantages over the Grobman's model, with regards to discrimination and calibration. For example, it increased predictive selection power near delivery.

The inclusion and exclusion criteria, employed in this study, were based on recent clinical guidelines, whereas the pre-delivery variables were increased by modifying the Grobman's model. These results are consistent with recent studies reporting that maternal BMI at delivery, history of vaginal delivery and maternal age at delivery are relevant or independent risk factors for successful TOLAC [12, 19-22]. Among these factors, history of vaginal delivery for predicting TOLAC success has been extensively reported [23]. In fact, maternal age is correlated with the success of TOLAC, despite the increase in the proportion of older pregnant women being affected by China's recent two-child policy. Given the previously reported differences in BMI, between different races [24], maternal BMI was a continuous variable in the model. In addition, results from LASSO screening indicated that maternal pre-pregnancy weight is not an independent risk factor for TOLAC's success, whereas maternal weight at delivery was associated with the success rate.

Bishop's score is a relatively subjective indicator for standardization. In the present study, we looked up the cervical bishop's score, two hours after regular uterine contractions, and simultaneously analyzed results from midwives and obstetricians. We found a positive correlation between Bishop's score and success of TOLAC, consistent with Francis (2005) who demonstrated a relationship between risk of cesarean delivery and unfavorable Bishop score at admission [25]. Similarly, several 
related studies have confirmed that the Bishop's score, at delivery, affects the success rate of TOLAC $[17,26]$. In the present study, the OR of Bishop's score was higher, with a relatively narrower confidence interval than that reported in previous studies (OR, 3.27; 95\% CI, 2.49 to 4.55). It is possible that previously reported models may have underestimated the role of standardized cervical evaluation.

Generally, previous studies have shown that maternal pelvis shape and fetal weight are the determining factors for the success of TOLAC $[13,21]$. However, estimating both parameters is challenging. In addition, a strong relationship has been reported between maternal pelvis shape and their height [27]. Results from the present study showed that higher pregnant women had a bigger chance of TOLAC success, suggesting that maternal height could be an independent factor for successful TOLAC. Determination of fetal weight by ultrasound scan results in low accuracy, and is also easily affected by the experience of the personnel performing it [28]. In addition, ultrasound scans are difficult to standardize the estimated weight, between different hospitals. Consequently, we chose the fundal height and maternal abdominal as the indicators for inclusion into the model, and found that fundal height was negatively associated with TOLAC success.

Previous studies have proposed the use of pregnancy at 40 weeks as a cut-off point for developing prediction models $[29,30]$. In the present study, we selected 39 weeks for delivered gestational weeks as a reference, based on the clinical guidelines. Similar results were observed using different cut-off values, with spontaneous uterine contractions before 39 gestational weeks found to be more conducive to successful delivery.

In this study, we did not evaluate performance on the hysterotomy scar, despite previous studies implicating it in prediction of TOLAC success [31]. This is because the examination is difficult to standardize, and is not conducive to further promote primary hospital, owing to the differences in experience of ultrasound practitioners as well as the associated examination methods. Recent evidence also suggests that models, based on the sonographic assessment of a hysterotomy scar, have poor accuracy in predicting successful VBAC [32].

This study had several limitations. Particularly, the study adopted a retrospective design, to recall of medical services received. Although we screened all vaginal trial cases, during the study period, some patients refused TOLAC and preferred repeat cesareans. In addition, a limited sample size presented a limitation to screening of clinical factors. Future studies are expected to include a bigger sample size to improve accuracy. Finally, we performed a single center analysis, targeting a population from Southeast China. Future studies are expected to include more populations across China and the world.

\section{Conclusions}

We successfully developed a model for predicting the success rate of TOLAC in Southeast China, to circumvent the current low ratio (20\%). The key strengths of this study are its inclusion and exclusion criteria, which were consistent with clinical guidelines. Our data also confirm the safety of TOLAC, in accordance with clinical guidelines. Overall, these findings are expected to guide obstetricians in southeast China to accurately predict TOLAC's success rate, and have a number of practical implications. However, generalization of the model is proposed to further validate and broaden its applications. Further prospective research and multicenter clinical trials are needed to validate and refine the model.

\section{Abbreviations}

TOLAC: Trial of Labor After Cesarean; VBAC: Vaginal Birth After Cesarean:" BMI: Body Mass Index; CS: Caesarean Section; CD: Cesarean Delivery; IQR: Interquartile range; SD: Standard deviation; LASSO: Least Absolute Shrinkage and Selection Operator; OR: Odds Ratio; Cl: Confidence interval

\section{Acknowledgements}

We thank Mr. Feng Lin (Department of Mechanics, Peking University) for his helping in revising the manuscript.

\section{Authors' contributions}

HLZ and JYY conceptualized the study. LCC, ZDL and LY acquired the data. $\mathrm{HLZ}$ and $\mathrm{LHZ}$ designed the analyses, QH and GYM performed the analyses. HLZ and LHZ wrote the draft manuscript. All authors read and approved the final draft of the manuscript for important intellectual content.

\section{Funding \\ This study was supported by the National Health and Family Planning Commission Science Foundation (2019-WJ-04), the Fujian Science and Technology Project (2018Y0005), and the Fujian Provincial Health and Family Planning Commission Youth Research Project (2019-2-10). The funding sources had no role in the study design, data collection, data analysis, data interpretation, or preparation of the manuscript.}

\section{Availability of data and materials}

Data were anonymized, and no patient information was included to preserve confidentiality. All data used to reach the aforementioned conclusions is available for scientific purposes, if needed.

\section{Ethics approval and consent to participate}

Ethical approval for this study was granted by the ethics committee of Fujian Provincial Maternity and Children's Hospital. Permission to access the anonymized (non-identified) data was granted by the Fujian Provincial Maternity and Children's Hospital Database steering committee.

\section{Consent for publication}

All data was anonymized, therefore individual consent for publication was not required.

\section{Competing interests \\ The authors declare that they have no competing interests.}

\section{Author details}

'Department of Obstetrics and Gynecology, Fujian Maternity and Child Health Hospital, Affiliated Hospital of Fujian Medical University, No.18, Daoshan Rd., Gulou Dist, Fuzhou City, Fujian province, China. ${ }^{2}$ Fujian Medical University, Fuzhou, China. 
Received: 17 May 2020 Accepted: 3 September 2020

Published online: 15 September 2020

\section{References}

1. Betran AP, Torloni MR, Zhang JJ, et al. WHO statement on caesarean section rates. BJOG Int J Obstet Gynaecol. 2016;123(5):667-70. https://doi.org/10 1111/1471-0528.13526.

2. Li HT, Luo S, Trasande L, et al. Geographic variations and temporal trends in cesarean delivery rates in China, 2008-2014. JAMA. 2017;317(1):69-76. https://doi.org/10.1001/jama.2016.18663.

3. Ma RMDT, Lao TT. VBAC should be encouraged as a means to reduce the caesarean section rate in China: FOR: VBAC reduces not only the caesarean section rate but also other associated issues. BJOG. 2016;123(Suppl):3 10.

4. Zeng $Y$, Hesketh T. The effects of China's universal two-child policy. Lancet. 2016;388(10054):1930-8. https://doi.org/10.1016/s0140-6736(16)31405-2.

5. Hehir MP, Ananth CV, Siddiq Z, et al. Cesarean delivery in the United States 2005 through 2014: a population-based analysis using the Robson 10-Group Classification System. Am J Obstet Gynecol. 2018;219(1):105.e1-05.e11. https://doi.org/10.1016/j.ajog.2018.04.012.

6. Obstetricians ACo, Gynecologists. ACOG Practice Bulletin No. 205: Vaginal Birth After Cesarean Delivery. Obstet Gynecol. 2019:133(2).

7. Wymer KM, Shih Y-CT, Plunkett BA. The cost-effectiveness of a trial of labor accrues with multiple subsequent vaginal deliveries. Am J Obstet Gynecol 2014;211(1):56. e1-56. e12.

8. Gynaecologists RCoOa. Birth after previous caesarean birth. Green-top Guide. 2015:45.

9. Association OGoGaOcoCM. Expert consensus on vaginal delivery management of second pregnancy after cesarean section (2016). Chin J Obstet Gynecol. 2016;51(8):561-5. https://doi.org/10.3760/cma.j.issn.0529$567 \times .2016 .08 .001$.

10. Landon MB, Hauth JC, Leveno KJ, et al. Maternal and perinatal outcomes associated with a trial of labor after prior cesarean delivery. N Engl J Med. 2004:351(25):2581-9.

11. Harris BS, Heine RP, Park J, et al. Are prediction models for vaginal birth after cesarean accurate? Am J Obstet Gynecol 2019; 220(5):492 e1-92 e7. doi: https://doi.org/10.1016/j.ajog.2019.01.232.

12. Grobman WA, Lai $Y$, Landon $M B$, et al. Development of a nomogram for prediction of vaginal birth after cesarean delivery. Obstet Gynecol. 2007;109: 806-12.

13. Wen J, Song $X$, Ding $H$, et al. Prediction of vaginal birth after cesarean delivery in Chinese parturients. Sci Rep. 2018;8(1):3084. https://doi.org/10. 1038/s41598-018-21488-6.

14. Li Y-X, Bai Z, Long D-J, et al. Predicting the success of vaginal birth after caesarean delivery: a retrospective cohort study in China. BMJ Open. 2019;9: 1-8. 10.1136

15. Xu P, Feng $Y$, Shen $H$, et al. Verification a model of predicting vaginal birth after cesarean delivery in Chinese pregnant women. Medicine (Baltimore). 2019:98(52):e18421. https://doi.org/10.1097/MD.0000000000018421.

16. Timmerman D. Re: Validation of prediction model for successful vaginal birth after Cesarean delivery based on sonographic assessment of hysterotomy scar. A. Baranov, K. A. Salvesen and O. Vikhareva. Ultrasound Obstet Gynecol 2018; 51: 189-193. Ultrasound Obstet Gynecol. 2018;51(2): 167. https://doi.org/10.1002/uog.18999.

17. Bellows P, Shah U, Hawley L, et al. Evaluation of outcomes associated with trial of labor after cesarean delivery after a change in clinical practice guidelines in an academic hospital. J Matern Fetal Neonatal Med. 2017; 30(17):2092-6. https://doi.org/10.1080/14767058.2016.1237498.

18. Lehmann $\mathrm{S}$, Baghestan $\mathrm{E}$, Bordahl PE, et al. Perinatal outcome in births after a previous cesarean section at high trial of labor rates. Acta Obstet Gynecol Scand. 2019;98(1):117-26. https://doi.org/10.1111/aogs.13458.

19. Goodall PT, Ahn JT, Chapa JB, et al. Obesity as a risk factor for failed trial of labor in patients with previous cesarean delivery. Am J Obstet Gynecol. 2005;192(5):1423-6. https://doi.org/10.1016/j.ajog.2004.12.075.

20. Lipschuetz M, Guedalia J, Rottenstreich $A$, et al. Prediction of vaginal birth after cesarean deliveries using machine learning. Am J Obstet Gynecol. 2020. https://doi.org/10.1016/j.ajog.2019.12.267

21. Manzanares S, Ruiz-Duran S, Pinto A, et al. An integrated model with classification criteria to predict vaginal delivery success after cesarean section. J Matern Fetal Neonatal Med. 2020;33(2):236-42. https://doi.org/10. 1080/14767058.2018.1488166.
22. Eden $K B, M c D o n a g h ~ M$, Denman $M A$, et al. New insights on vaginal birth after cesarean: can it be predicted? Obstet Gynecol. 2010;116(4):967-81.

23. Denham SH, Humphrey $\mathrm{T}$, de Labrusse $\mathrm{C}$, et al. Mode of birth after caesarean section: individual prediction scores using Scottish population data. BMC Pregnancy Child. 2019;19(1):84. https://doi.org/10.1186/s12884019-2226-6.

24. Camhi SM, Bray GA, Bouchard C, et al. The relationship of waist circumference and BMI to visceral, subcutaneous, and total body fat: sex and race differences. Obesity. 2011;19(2):402-8.

25. Vrouenraets FP, Roumen FJ, Dehing CJ, et al. Bishop score and risk of cesarean delivery after induction of labor in nulliparous women. Obstet Gynecol. 2005;105(4):690-7. https://doi.org/10.1097/01.AOG.0000152338. 76759.38.

26. Lin J, Hou Y, Ke Y, et al. Establishment and validation of a prediction model for vaginal delivery after cesarean and its pregnancy outcomes-based on a prospective study. Eur J Obstet Gynecol Reprod Biol. 2019;242:114-21. https://doi.org/10.1016/j.ejogrb.2019.09.015.

27. Fischer B, Mitteroecker P. Covariation between human pelvis shape, stature, and head size alleviates the obstetric dilemma. Proc Natl Acad Sci. 2015: 112(18):5655-60. https://doi.org/10.1073/pnas.1420325112.

28. Kacem Y, Cannie MM, Kadji C, et al. Fetal weight estimation: comparison of two-dimensional US and MR imaging assessments. Radiology. 2013;267(3): 902-10

29. Mooney SS, Hiscock R, Clarke ID, et al. Estimating success of vaginal birth after caesarean section in a regional Australian population: validation of a prediction model. Aust N Z J Obstet Gynaecol. 2019;59(1):66-70. https://doi. org/10.1111/ajo.12809.

30. Grisaru-Granovsky S, Bas-Lando M, Drukker L, et al. Epidural analgesia at trial of labor after cesarean (TOLAC): a significant adjunct to successful vaginal birth after cesarean (VBAC). J Perinat Med 2018;46(3): 261-269. doi: https:// doi.org/10.1515/jpm-2016-0382 [published Online First: 2017/06/18].

31. Naji $O$, Wynants $L$, Smith $A$, et al. Predicting successful vaginal birth after cesarean section using a model based on cesarean scar features examined by transvaginal sonography. Ultrasound Obstet Gynecol. 2013;41(6):672-8. https://doi.org/10.1002/uog.12423.

32. Baranov A, Salvesen KA, Vikhareva O. Validation of prediction model for successful vaginal birth after cesarean delivery based on sonographic assessment of hysterotomy scar. Ultrasound Obstet Gynecol. 2018;51(2):189 93. https://doi.org/10.1002/uog.17439.

\section{Publisher's Note}

Springer Nature remains neutral with regard to jurisdictional claims in published maps and institutional affiliations.

Ready to submit your research? Choose BMC and benefit from:

- fast, convenient online submission

- thorough peer review by experienced researchers in your field

- rapid publication on acceptance

- support for research data, including large and complex data types

- gold Open Access which fosters wider collaboration and increased citations

- maximum visibility for your research: over $100 \mathrm{M}$ website views per year

At BMC, research is always in progress.

Learn more biomedcentral.com/submissions 